\title{
Academic Outcomes in Language-Dependent and Computation-Dependent Courses among Mathematics Education Students in a Nigerian University: Top-Achievers Still Best of both Extremes
}

Joshua Abah *

\begin{abstract}
In the field of mathematics education, there is an increased awareness of the need to account for the connection between mathematics and language. Despite the emphasis on this existing interconnectivity, students often erroneously distinguish themselves as better oriented to one extreme or the other. This study explores the pattern of academic performance of mathematics education students in language-dependent and computation-dependent courses. The study built on the Monitor Theory of second language acquisition to observe that school works existing as the practical result of learned language and grammar are among the reasons some students unnecessarily fear language-dependent courses. Ex-post facto research design was adopted to analyze the scores of 48 students enrolled in a programme in mathematics education at a university in North Central Nigeria. A total of 29 core courses across six (6) semesters were split into two dichotomous extremes of language-dependent and computation-dependent based on content and scope. Each student's scores were averaged across each category, with the absolute difference between the two averages taken as measure of achievement gap between the two extremes. A paired samples $t$-test of students average scores in the two categories indicates a statistically significant difference ( $t 0.05,47=7.3244, p=0.000$ ). Further analysis shows that $41.67 \%$ of the students are language-dependent, $2.08 \%$ computation-dependent, and $56.25 \%$ not dependent on any of the extremes. Additional analysis of variance (ANOVA) among three (3) identified performance categories reveals that the achievement gap differ significantly among bottom, middle and top achievers, with the mean achievement gap lowest among top Achievers. The findings of this study stressed the reality of inherent and superficial categorization based on the two extremes among mathematics education students. The interpretation of the findings in terms of students' unique orientation and mindset towards mathematics education were also discussed. Based on the findings of the study, it was recommended that future works may consider introducing corroborative information about participant's inclination toward the two extremes to strengthen eventual placement from attainment scores.
\end{abstract}

Keywords: Mathematics education, language-dependent, computation-dependent, mathematical mindset, top achievers

\section{Introduction}

Learning mathematics requires multiple and complex linguistic skills that second language learners may not have mastered. Emphasis on language in the teaching and learn-

\footnotetext{
*Department of Science Education, University of Agriculture, Makurdi, Nigeria. Email: abahjoshua.a@gmail.com
} 
ing of mathematics is essential if Nigerian students, who are de facto English Language Learners, are to have a solid footing in the current information age. In today's mathematics classrooms, students must deal with communication demands (oral and written) that require participation in mathematical practices such as explaining solution processing, making and describing conjectures, proving conclusions and presenting arguments and justifications (Perez \& Pugalee, 2009). For students in Nigerian higher education, this fact has an added dimension. Mathematics education students, for instance, are required to be proficient, not just in the computational routines of mathematics, but also in articulately transferring mathematical knowledge to others in clear language (Abah, 2017). By implication, the training of mathematics education students as pre-service teachers requires the comprehensive and compulsory taking of courses across the language-computation continuum. Consequently, it is common knowledge that some of these students consider themselves proficient in one area and not the other (Boaler, 2015). A young pre-service mathematics teacher, Oguche, is a glaring example of this biased orientation of students about language-dependent courses and purely computational ones.

It is always a cause for worry whenever Oguche thinks about preparing for his General Studies examinations. But the opposite is obtainable for his Mathematics courses. Other students of Mathematics education consider Oguche lucky to have had a sound Mathematical background from an unpopular pre-university Advance-Level programme before gaining admission into the University. He seems to have a full grasp of Mathematical concepts and is indeed proficient in Mathematics as evidenced in his high grades in Mathematics courses. Basically, Oguche is the first point of call for many of his classmates struggling to pass Mathematics courses. But Oguche sees himself differently. He would have been the happiest Mathematics education student around if only all his General Studies and Educational Methodology courses are swapped with more computational ones. He often voiced out his frustration with what he termed "endless reading and writing." To copy with this seeming phobia, Oguche is forced to put in extra work and time reading and decoding his language-dependent courses. For instance, if an examination for a language-dependent course unit is slated for the last day on the examination timetable, Oguche would be seen reading and re-reading this course right from the very first day the timetable was released. While it takes a night or two to completely summarize any of his Mathematical courses in preparation for examination, Oguche will have to study his non-computational courses in detail, even after every successful day of preparation for Mathematics. These coping strategies are seen as survival mechanisms by the young man, considering the outcome that he always barely scale through the languagedependent courses all through the lifecycle of the first degree programme in Mathematics education. The phenomenon reduced Oguche to an average graduate of Mathematics education and he was grateful that this personal battle was finally over. Oguche's second degree is, of course, in Pure Mathematics and he is at peace with the computational-nature of the Masters programme he is currently enrolled in.

Instances such as the foregoing are common in the Nigerian educational system. Nigeria, being a previous British Colony, adopted the English language as her Lingua Franca at Independence in 1960. Ever since then, it has become mandatory to learn English Language at all levels of formal education in the country. Basic requirements for entry into 
higher educational institutions include a credit pass in English Language. This requirement is also required also obtains for entry into all post graduate programmes in Nigerian Universities.

Apart from being a basic requirement for admissions, Use of English is often taken as a compulsory general studies course for all new entrants into Nigerian higher education. For the Mathematics education programmes, the Benchmark Minimum Academic Standard (BMAS) of National Universities Commission (NUC) recommends Use of English and Library and other General Studies as foundational courses to be taken across the first two semesters National Universities Commission-NUC (2007). The reason for this special attention to English Language is not far-fetched. Put simply, it is the language of communication, teaching and research in Nigeria.

Several studies have substantially established the connection between English language proficiency and academic performance among different classes of learners (Henry, Nistor, \& Baltes, 2014; Prendergast, Faulkner, \& O' Hara, 2015). This is apparently because language competence allows one to use it as an organizer of knowledge and as a tool for reasoning (Fite, 2002). This is also very true in Mathematics Education where the expectation for students is not merely to memorize formulas and rules and apply procedures but to engage in the process of mathematical thinking (Ladson-Billings, 1997 in Fite (2002). Likewise, since learning occurs in a social context, students' experience of success in Mathematics is deeply embedded in everyday experiences, including interaction with language. In Nigeria, though English language is an essential requirement, proficiency among students varies widely, with diverse attendant consequences. In other words, learning mathematics in a different language provides the learners with a different perspective on the content area; different vocabulary creates further associations; different methods necessary for instruction through a foreign language like English can trigger more active approach and deeper understanding (Prochazkova, 2013). Students' inability to differentiate and establish relationships between vocabularies, notations, formulae and symbols; as well as their lack of understanding of the special use of language in mathematics all contributed to their poor achievement in mathematics (Iji, Agbo-Egwu, \& Adikwu, 2014). Personal approaches to study and basic educational background are fundamental in determining the impact of the lingua franca on the academic performance of students in the country (Abah, 2017). Students who grew up in homes that support extensive reading and writing are definitely not expected to struggle with comprehending textual materials and communication their points of view in assessments. Parents who have a lot books around the house might encourage a child to get more into reading and writing, whereas Mathematical games promote doing sum instead (Hadhazy, 2011). Conversely, those without a sound background in reading and writing tend to struggle through school. This second group often finds reading of lecture materials a huge task in itself.

With particular reference to Mathematics Education, teachers and educators at all levels of education are constantly encouraged to deliver instruction with an awareness of language barrier. The Instruction Division of the Virginia Department of Education outlined five key elements of an effective language learning environment. The use of these strategies according to Virginia Department of Education (2004) can assist all students in 
accessing the content material:

i. Comprehensive Input: Teachers can make their language more comprehensible by modifying their speech, adjusting teaching materials, and adding context to lessons.

ii. Reduced Anxiety Level: A student's emotions play a pivotal role in assisting or interfering with learning a second language. Teachers can assist students by creating a comfortable classroom environment that encourages participation and risk-taking without fear of feeling embarrassed or foolish.

iii. Contextual Clues: Visual support makes language more comprehensible. For example, a lesson about fractions using manipulative is more understandable than an explanation of the concept.

iv. Verbal Interaction: Students needs opportunities to work together to solve problems and use English for real, meaning purposes. They need to give and receive information and complete authentic tasks.

v. Active Participation: Lessons that encourage active involvement motivates Limited English Proficient (LEP) students, engage them in the learning process, and help them remember content more easily.

Observations have shown that Nigerian higher educational institutions hardly consider LEP students in the design and delivery of instruction. The usual assumption is that having scale through tight English language admission requirements, a student in the higher institution should have overcome all language-based challenges. But this assumption is far from the reality on ground, particularly among students of Mathematics Education. The mere choice of Mathematics-related programmes by some students is often predicated on the fear of extensive reading and writing. At the early stage, these students are often unaware of the details of the Mathematics Education Curriculum as spelt out in the BMAS. They often find out in the course of the programme that as well as computational courses, methodology and language-based courses share almost equal attention and significance.

Basically, a course is considered language-dependent if it has little to do with mathematical calculations and algorithms. Courses in this category comprise almost $50 \%$ of the total credits expected to be covered in a typical programme in mathematics education. Language-dependent courses are more theoretical and usually come with expansive content materials, textbooks and online reading. In this respect, many teaching methodology courses and general studies could be considered language-dependent. On the other hand, computation-dependent courses are core mathematical and statistical courses that do not require extensive writing. Some computer science courses bordering on algorithm and programming also fall into this category. This categorization, as descriptive as it is, is at best superficial, and has never featured in any official document of any University or the NUC. Evidently, the Mathematics Education programme is a composite one and as such students are required to face all prescribed course units with equal seriousness to enable them attain the minimum graduation requirement. 
The superficial classification of study units as computation-dependent or languagedependent has featured predominantly in ongoing discussions on the mindset of mathematics. The preposition that "some people just can't do mathematics" has been ongoing for years (Willingham, 2009). Hadhazy (2011) puts the debate thus:

"Most people would agree they are better at verbal or math subjects in schools, as grades usually do attest. Highly intelligent individuals often do well in both subjects while less intelligent people can struggle. But a minority of learners do very well in math and poorly in language and vice versa. These extremes in ability relates to the very makeup of the brain."

With respect to the makeup of the brain, an in-depth report by the Organization for Economic Co-operation and Development OECD (2007) agree that there are optimal or "sensitive periods" during which particular types of learning are most effective, despite the lifetime plasticity of the brain. Dickerson (2013), however, asserts that contrary to popular opinion, a natural ability in mathematics will only get you so far in studies of the subject. Dickerson (2013) clarifies that research published in Child Developments found that hard work and good study habits were the most important factor in improving mathematics ability over time.

Among mathematics education students in Nigeria, there exist a wide range of orientation about mathematics ability. Personal observation has also unveiled some students' distaste for either language- dependent course units or computation-dependent ones. But there is little or no empirical exposure on this subject matter from within the country. Therefore, this present study is a novel attempt to understand the spread of academic performance of mathematics education students in Nigeria across both extremes. Do these students actually respond differently to language- dependents course units and computation- dependent ones? If this difference exists, is it statistically significant? How does the achievement gap between language- dependent courses and computation-dependent courses differ among the identified performance categories of mathematics education students? These and other pertinent concerns form the basis of this investigation.

\section{Theoretical Foundations}

Since the early 1900s, several theories, methods, and hypotheses have acted as theoretical foundations for the use of a second language in the transfer of knowledge. Popularly held theoretical ideas include Bloomfield and Fries (Audio-lingual and Direct Method), Skinner (Behaviourist S-R-R), Chomsky and Krashen (Universal Grammar and Language Acquisition Device), Anderson and McLaughlin (Information Processing Models), and Vgotsky and Snow (Social Interactionism). Though all these perspectives hold their relative significance in the study of second language acquisition, only Krashen's Monitor Model will be considered here in detail.

Stephen Krashen developed the Monitor Model of second language acquisition in the 1970s using ideas developed by Chomsky. According to Krashen (2002), language acqui- 
sition is very similar to the process children use in acquiring first and second language. It requires meaningful interaction in the target language - natural communication- in which speakers are concerned not with the form of their utterances but with the messages they are conveying and understanding. Krashen maintained that error correction and explicit teaching of rules are not relevant to language acquisition, but caretakers and native speakers can modify their utterances to acquirers to help them understand. But on the other hand, conscious language learning, the type indulged in by Nigerians, is thought to be helped a great deal by error correction and the presentation of explicit rules. Error correction, it is maintained, helps the learner come to the correct mental presentation of the linguistic generalization.

The fundamental claim of the Monitor Theory is that conscious learning is available to the performer as a Monitor (Krashen, 2002). The Monitor is a control system that can alter the output of the acquisition system according to learned rules.

In general, utterances are initiated by the acquired system; the fluency in production is based on what have been picked up through active communication. The formal knowledge of the second language, the conscious learning, may be used to alter the output of the acquired system, sometimes before and sometimes after the utterance is produced. These changes are made to improve accuracy, and the use of the Monitor often has this effect (Krashen, 2002). The Natural Approach encourages appropriate and optimal use of the Monitor. Students are expected to use the conscious grammar when they have time, when the focus is on form, and when they know the rule. This occurs mostly in written work, in prepared speech, or on homework assignments (Krashen, 1995). They are not expected to apply rules consciously in the oral communicative activities of the classroom. The functioning of the Monitor (or editor) in the production of student works in language-dependent courses is what some students of Mathematics Education exaggerate in their dislike for course units that demands extensive comprehension and writing. School works that exist as the practical result of the learned grammar (Hong, 2008) are among the reasons some students unnecessarily fear language-dependent courses. For such students, the language demands (or thresholds) for demonstrating educational achievement increases with each year of academic progress (Roessingh, Kover, \& Watt, 2005).

Further theoretical expositions that challenge some basic assumptions about mathematics are provided by current advances in neuroscience. According to Boaler (2015), the most popular and damaging of these assumptions has been that some people can do mathematics and others just cannot. This assumption has discouraged a lot of students from sticking with the subject, and some parents and teachers are beginning to believe it. The Organization for Economic Co-operation and Development OECD (2007) report simplified some key facts exposed by neuroscience with respect to the involvement of the brain in learning.

i. Neuroscientists have well established that the brain has a highly robust and welldeveloped capacity to change in response to environmental demands, a process called plasticity.

ii. For sensory stimuli such as speech sounds, and for certain emotional and cognitive 
experiences such as language exposure, there are relatively tight and early sensitive periods. Other skills such as vocabulary acquisition, do not pass through tight sensitive periods and can be learned equally well at any time over the lifespan.

iii. Many of the environmental factors conducive to improved brain functioning are everyday matters the quality of social environment and interactions, nutrition, physical exercise, and sleep which may seem too obvious and so easily overlooked in their impact on education. By conditioning our minds and bodies correctly, it is possible to take advantage of the brain's potential for plasticity and to facilitate the learning process.

iv. Although the brain is biologically primed to acquire language right from the very start of life, the process of language acquisition needs the catalyst of experience. Adolescents and adults, of course, can also learn a language anew, but it presents greater difficulties.

v. Numeracy, like literacy, is created in the brain through the synergy of biology and experience.

Similarly, Boaler (2013) observed that new understanding of the brain, ability and learning has important implications for schools, in particular, the ability based practices and messages that prevail. In line with the phenomenal work of Carol Dweck, mathematics educators have being encouraging students to develop a growing mindset which believe that intelligence and smartness can be learned and that the brain can grow from exercise. Students with a growth mindset work and learn more effectively, displaying a desire for challenge and resilience in the face of failure (Boaler, 2013). In emphasizing that one do not have to be a genius to do mathematics, Tao (2017) points out that in order to make good and useful contributions to mathematics, one does need to work hard, ask questions and think about the "big picture." Tao (2017) added that the objective in mathematics is not to obtain the highest ranking, but to increase the understanding of mathematics both for oneself and others and to contribute to its development and applications.

In the same vein, (Willingham, 2009) observes that while it is true that some people are better at mathematics than others, it is also true that a vast majority of people are fully capable of learning mathematics. Learning mathematics only takes time and effort, and requires mastering increasingly complex skills and content. Willingham (2009) added that virtually everyone is fully capable of understanding arithmetic procedures, algebra, geometry, and probability deeply enough to allow applications to problems in our daily lives. The self-destructive idea of "math people" only perpetuates the pernicious myth of inborn genetic math ability (Kimball \& Smith, 2013). Inborn talent is much less important than hard work, preparation, and self-confidence with respect to proficiency in mathematics. Kimball and Smith (2013) added that people's belief that mathematics ability cannot change often becomes a self-fulfilling prophecy.

Butterworth (2017) suggests that one of the things that distinguishes people who are good at mathematics to have effective "mathematical brain" is an ability to see a problem 
in different ways. Such people use a range of different procedures to solve a particular problem because they understand it. People who are "bad at mathematics" stick to one procedure, sometimes the inappropriate one, because that is the only one they know and feel sure about. To rid oneself of mathematics anxiety, Butterworth (2017) proposes a three-step programme of slowing down, trying to understand, and doing mathematics upside down.

The few theoretical works considered here have underscore that although our brains are evolutionarily hard-wired for speech and a basic sense of numbers, we must be taught to read, write and do mathematics (Hadhazy, 2011). Regardless of one's natural abilities, practice to an extent can make perfect across both language-dependent and computationdependent course works.

\section{Empirical Studies}

It has been common knowledge for quite some decades that language proficiency, no matter how it is measured, is related to mathematics achievement (Fite, 2002). Several past empirical works, early and more recent, display the dynamism of language in knowledge acquisition across diverse spectrum of learners.

Sahragard, Baharloo, and Soozandehfar (2011) undertook a study to find the relationship between Iranian College students' language proficiency and their academic achievement. A sample of 151 female and male students majoring in English at an Iranian University participated in the study. A proficiency test which was a truncated version of Test of English as a Foreign Language (TOEFL) with a KR-21 reliability value of 0.76 was the major instrument of the study along with the students Grade Point Average (GPAs). The analysis of the research data revealed that there is a significant positive relationship between language proficiency and academic achievement. The results of the independent t-test indicated that female participants did not differ significantly with regard to their language proficiency and academic achievement.

Similarly, Arsad, Bauniyamin, and Manan (2014) presented the results of an investigation that compares the performance in English courses of male and female students of a bachelor level engineering programme at a Malaysian University. Students' performance was measured based on their Cumulative Grade Point Average (CGPA) upon graduation. The outcomes of the study indicated that there appears to be direct correlation between students' result for Fundamental (English) Courses and the final overall academic performance of graduating students.

Relatedly, using an ex-post facto, non-experimental approach, Martirosyan, Hwang, and Wanjohi (2015) examined the impact of English language proficiency and multilingualism on the academic performance of international students enrolled in a four-year programme at a University located in North Central Louisiana in the United States. Data were collected through a self-reported questionnaire from 59 students. Statistical analyses revealed significant differences in language proficiency and multilingualism in relation to academic performance. The highest mean GPA was evident among students who had reported high levels of self-perceived English language proficiency and among students 
who spoke at least three languages.

An extensive review by Fite (2002) established that vocabulary, number and symbol sense, as well as the ability to read and comprehend word problems are important factors affecting achievement in mathematics. The cognitive ability that drives symbol processing is the connection between language and mathematics, with the difference in syntax of both areas creating a kind of divergence. Fite (2002) maintained that good reading, writing and grammatical skills do not in any of themselves translate into good arithmetic computational and problems solving skills. However, poor language skills do correlate with poor mathematics skills, suggesting that both require a basic level of competency in symbol processing. Both need to be taught and learned (Fite, 2002). Both require a working knowledge of the interaction of numerous discrete skills. This explains why the incorrect assumption that students transfer skills used in reading story selections to reading word problems often lead many students who score well on language-dependent tests not to score well on tests of mathematical problem solving (Fite, 2002). These lines of reasoning are fully supported by the empirical work of Henry et al. (2014) whose analysis revealed English proficiency as a statistically significant predictor of mathematics scores.

These empirical works and many others in their class attest to the difference observed among students along the language-computation continuum, but stopped short of exploring the dynamics of students claiming favorable disposition towards one extreme only and not the other. This present study differs from the empirical works reported in available literature in its emphasis on the two extremes of language-dependence and computation-dependence. The study focuses on mathematics education students academic performance across these extremes with respect to identified ability levels. The diverse statistical approach to data handling and presentation in this current work is intended to shed more light on the pattern of mathematics education students' overall performance over a long period of time (six semesters) and raise awareness on the superficial existence of polarized students' orientation about mathematics.

\section{Methodology}

This study adopted the ex-post facto research design. The ex-post facto research design is a research in which the independent variable of interest has already occurred and in which the researcher begins with the observation on a dependent variable, followed by a retrospective study of possible relationship and impact (Emaikwu, 2012). The ex-post facto design was considered appropriate for the study due to its scope of coverage in explaining existing relationships and developing trends.

Data used in this study comes from the examination records of forty-eight (48) students of Mathematics Education enrolled in a federal University in North Central Nigeria. Three (3) academic sessions, comprising six (6) semesters, beginning from the First Semester of the 2012/2013 academic session to the Second Semester of the 2014/2014 academic session, were considered. This implies that only academic achievement scores of the 48 mathematics education students in their first three years of study were considered. Based on their Cumulative Grade Point Average (CGPA) at the end of the third 
year (300 Level), the students were clearly demarcated into three (3) distinct performance categories. These are Bottom (1.00 - 1.99), Middle (2.00 - 2.99), and Top (3.00 - 5.00). The University uses a 5 - point CGPA system.

In each semester, language-dependent courses and computation-dependent courses were identified based on course contents. This identification gave rise to a total of 17 courses that invariably requires extensive reading, grammar and writing (language- dependent), and a total of 12 courses that are basically computational and requires little grammatical composition and lengthy writing. Courses that are practical in content and scope such as Entrepreneurship Practice were left out of this categorization, alongside field works (Teaching Practice) and Project work. To arrive at the achievement gap in these two broad areas, each student's scores across the language-dependent course units were averaged. Same applied to the student's scores across all computation-dependent courses. The absolute difference between the two averages per student gives the achievement gap.

Both descriptive and inferential statistical tools were used in analyzing the data obtained in this study. Mean and simple percentages were used to answer the research questions. In determining the dependence category of a student, an achievement gap value below the benchmark mean (of all achievement gap values) indicate "Not Dependent" while an achievement gap value above the benchmark mean in favour of languagedependent courses (i.e. higher average in language-dependent courses) indicate "Dependent on Language", and an achievement gap value above the benchmark mean in favour of computation-dependent courses (i.e. higher average in computation-dependent courses) indicate "Dependent on Computation." These three (3) dependence categories are mere labels in describing each students orientation towards mathematics education as a programme or discipline. The first hypothesis was tested at 0.05 level of significance using a paired-samples t-test. The second hypothesis was tested at 0.05 level of significance using a single-factor Analysis Variance (ANOVA).

To protect the privacy of the students used in this study, names of students were coded with alphabets and numbers representing each student. For instance, S1 stands for student number 1, while S48 is for student number 48. The records used for this study are obtained with appropriate permission of the Departmental Examination office in charge of the students examination records.

\section{Results}

The results of this study are presented according to the research questions and hypotheses.

Research Question One: What is the pattern of language-dependence among mathematics education students?

The distribution shown in Table 1 presents the general pattern of language dependence among mathematics education students. From the summary in Table 2, it is clear that a larger proportion $(56.25 \%)$ of mathematics education students does not lean to- 


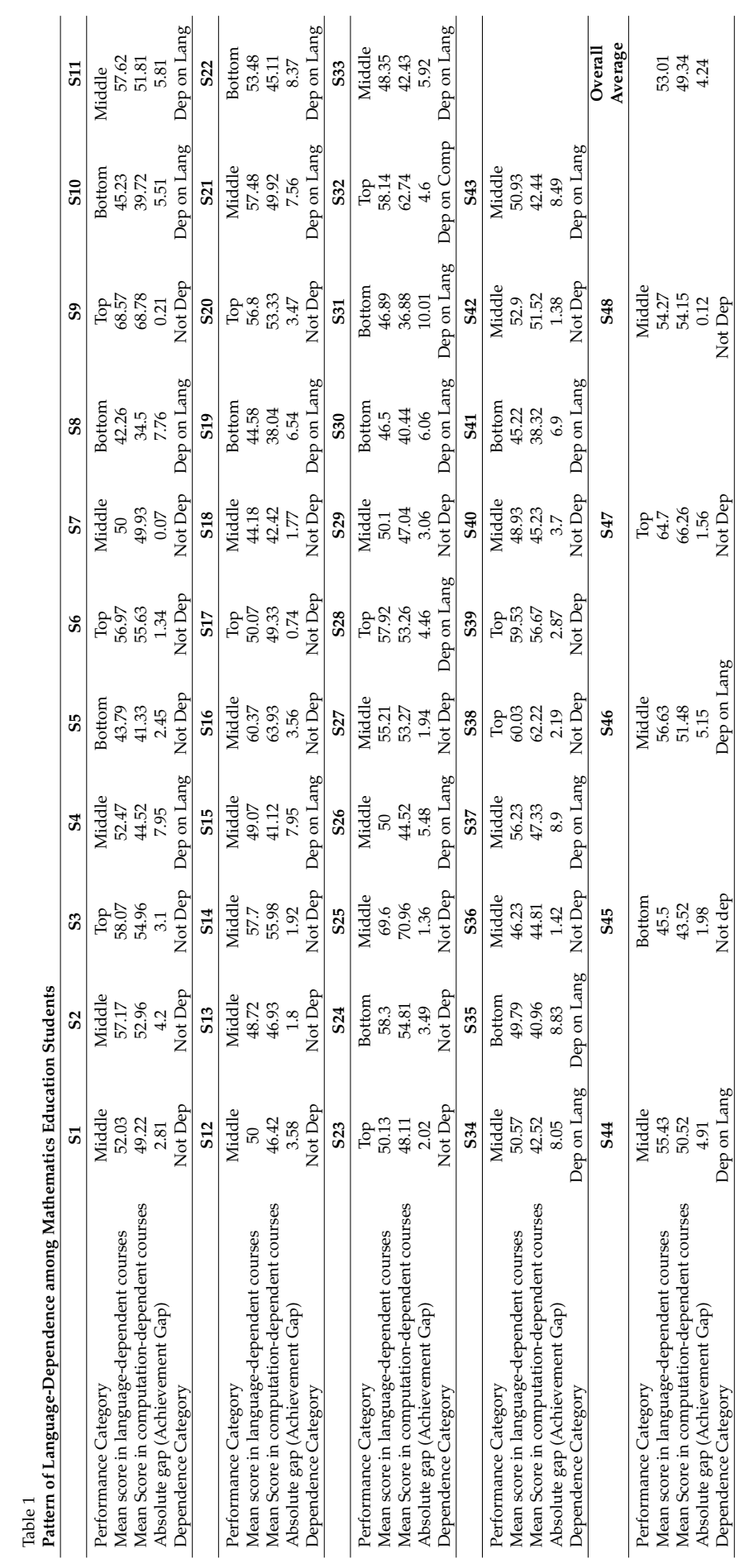


wards any of the two extremes, an indication of the right orientation towards their chosen field of study.

\begin{tabular}{lcc} 
Table 2 & \\
Summary of Language Dependence Pattern & \\
\hline Dependence Category & Number of Students & Percentage (\%) \\
\hline Not dependent & 27 & 56.25 \\
Language-dependent & 20 & 41.67 \\
Computation-dependent & 1 & 2.08 \\
\hline
\end{tabular}

Twenty mathematics education students' constituting $41.67 \%$ of the participants of this study lean towards language-dependence, implying that they tend to perform better in course units that entails extensive reading, grammar and composition. However, a student $(2.08 \%)$ was found to be computation-dependent.

Research Question Two: What is the proportion of dependence among the three performance categories of mathematics education students?

Table 3

Language-Dependence based on performance category

\begin{tabular}{lccc}
\hline $\begin{array}{c}\text { Performance } \\
\text { Category }\end{array}$ & $\begin{array}{c}\text { Number of } \\
\text { Students in } \\
\text { category }\end{array}$ & $\begin{array}{c}\text { Number of } \\
\text { Dependent students } \\
\text { in category }\end{array}$ & $\begin{array}{c}\text { Percentage (\%) } \\
\text { of dependent } \\
\text { in category }\end{array}$ \\
\hline Bottom & 11 & 8 & 72.73 \\
Middle & 24 & 11 & 45.83 \\
Top & 13 & 2 & 15.38 \\
Total & 48 & 21 & - \\
\hline
\end{tabular}

The results in Table 3 show that $72.73 \%$ of Bottom Achievers exhibit one form of dependence or the other. Likewise, $45.83 \%$ of middle achievers display one form of dependence or the other. By cross-referencing Table 1, it is easy to deduce that both Bottom and Middle Achievers exhibit language-dependence. This indicate that $72.73 \%$ of Bottom Achievers and $45.83 \%$ of Middle Achievers are actually language-dependent, performing better in educational methodology courses and general studies than in pure mathematics and computational courses.

From Table 3, it is notable that only 2 students (i.e. 15.38\%) out of 13 Top Achievers exhibit dependence of any form. According to Table 1, one student among the Top Achievers is language-dependent while the other is computation-dependent, in fact, the only one across this study.

Hypothesis One: There is no significant difference between the mean achievement scores of mathematics education students in language-dependent courses and computation- dependent courses. 


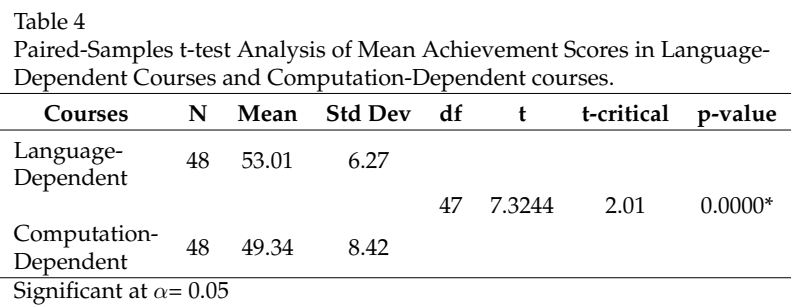

The result of the paired-samples t-test analysis shown in Table 4 indicated that there is a significant difference $(\mathrm{p}=0.000)$ between the mean achievement scores of mathematics education students in language-dependent courses and computation-dependent courses. Since the calculated $t$ value of 7.3244 is greater than the critical $t$ value of 2.01 , the null hypothesis of no significant difference is rejected. This outcome implies that each student's performance in language-dependent courses is uniquely different from his/her performance in computation-dependent courses, underscoring the existence of wide spread polarization in each student's orientation towards mathematics education.

Hypothesis Two: There is no significant difference in the achievement gap between language-dependent courses and computation-dependent courses among the three performance categories of mathematics education students.

Table 5

\begin{tabular}{lcccccc}
\multicolumn{6}{l}{ Analysis of Variance (Single-factor ANOVA) Data Description } \\
\hline $\begin{array}{l}\text { Performance } \\
\text { Category }\end{array}$ & N & Sum & Mean & Variance & $\begin{array}{c}\text { Sum of } \\
\text { Squares }\end{array}$ & SE \\
\hline Bottom & 11 & 65.76 & 5.98 & 7.898496 & 78.98496 & 0.761426 \\
Middle & 24 & 103.43 & 4.31 & 8.139422 & 187.2067 & 0.515488 \\
Top & 13 & 34.13 & 2.63 & 1.732844 & 20.79412 & 0.70041 \\
\hline
\end{tabular}

Table 6

ANOVA (Single-Factor)

\begin{tabular}{lcccccc}
\hline \multicolumn{1}{c}{ Sources } & Sum of squares & df & Mean Square & F & F-critical & p-value \\
\hline Between groups & 67.24018 & 2 & 33.62009 & & & \\
Within Groups & 286.9858 & 45 & 6.377462 & 5.271704 & 3.204317 & $0.008771^{*}$ \\
Total & 354.226 & 47 & 7.536723 & & & \\
\hline * Significant at $\alpha=0.05$ & & & & &
\end{tabular}

The ANOVA result displayed in Table 6 indicate that there is a significant difference $(p=0.008771)$ in the achievement gap between language-dependent courses and computation-dependent courses among the three performance categories of mathematics education students. Since the calculated F-value of 5.271704 is greater than the critical Fvalue of 3.204317, the null hypothesis of no significant difference is rejected. This outcome implies that the achievement gap differ significantly among Bottom Achievers, Middle Achievers, and Top Achievers.

Further information about the "behavior" of the achievement gap between languagedependent courses and computation-dependent courses among mathematics education 
students can be obtained from a simple contrast of the means of the three performance categories as shown in Table 5. The mean achievement gap is highest among Bottom Achievers but Lowest among Top Achievers.

\section{Discussion}

The results of this study have demonstrated the pattern of language-dependence among mathematics education students. Specifically, the distribution of students' mean scores in courses across the two extremes (Language-Dependent and Computation-Dependent) has shown that $41.67 \%$ of the students considered in this study perform reasonably better in language-dependent courses. This group of students seems to be comfortable with extensive reading and writing in the course of their study, and may actually prefer less computational work. But the opposite is the case for student S32, a Top Achiever, who is evidently computation-dependent. However, a good proportion (56.25\%) of the students neither lean towards language nor computation. The performance of this neutral group points to a composite approach to study which involves the ability to derive meaning from symbols whether they be letters, words, numbers, or equations (Fite, 2002). A critical look at Table 1 indicates that proportionately, this later group of non-dependent students are Top Achievers (12 out 13 Top Achievers are neutral).

Further deductions from Table 3 indicate that the widest disparity between achievements scores in language courses and computation courses exists among Bottom Achievers (72.73\% of Bottom Achievers are Language-dependent). Cross-referencing with Table 1 reveals margins as wide as 10.01 (S31), 8.83 (S34) and 7.95 (S15), among Bottom Achievers. Similar margins $(8.49,8.37$, and 8.05$)$ can also be seen among Middle Achievers, whereas the highest margin among Top Achievers is 4.60 (Slightly above the benchmark mean of 4.24). This finding is in line with the assertion by Hadhazy (2011) that highly intelligent individuals often do well in both Language and Computational courses, while less intelligent people can struggle. Similarly, the outcome that one student among the Top Achievers is language-dependent while another is computation-dependent agrees with Tao (2017) who observed that at any point in time, some mathematicians are faster, more experienced, more knowledgeable, more efficient, more careful, or more creative than others.

The analysis of Hypothesis One established a significant difference between the mean achievement scores of mathematics education students in language-dependent courses and computation-dependent courses. Similar variations were also observed by Ebrahim and Dagnaw (2015). This finding stressed the reality of the superficial categorization based on the two dichotomous extremes of extensive writing courses and calculationbased ones, at least inherently among students of mathematics education. These unique orientations may be interpreted as the existence of fixed mindset beliefs that contributed to wide inequalities in education (Boaler, 2013). The fact that the outcomes presented in this study spans a period of six (6) Semesters is indicative of students lack of belief that their ability in mathematics grow with attendant improvement in achievement. When considered in the light of Table 1 where majority of students performed better in 
Language-dependent courses, this finding supports (Wall, 2016) who reported that after a State-wide test of Californian students, fewer than half of students scored at or above English language standards while barely one third hit these levels in mathematics.

Contrasting the means from the analysis of Hypothesis One as displayed in Table 5 adds more evidence to the outcome that disparity in academic achievement in languagedependent courses and computation-dependent courses is lowest among Top Achievers. This category of mathematics education students evidently possesses the ability to communicate by clarifying and justifying their ideas and procedures, affirming that language and competence in mathematics are not separable (Pugalee, 2009). This small class of mathematics education students must have shown reasonable metacognition or selfmonitoring and for them the application of varied learning strategies may have assisted in comprehending language-leaning courses. The Top Achievers must have mastered the sociocultural dimension of the school system which represents a complex interplay between the physical world and how those in discourse communities construct meaning through language (Abah, 2017). The sociocultural dimension, according to Pugalee (2009), involves norms, values, beliefs, attitudes and practices of language within cultural settings which include the learning environment. The students' strategic competence mediated by language ultimately impacted their ability to formulate, represent, and do mathematics.

The Analysis of Variance (ANOVA) establishes a statistically significant difference in the spread of the achievement gap in the two areas among Bottom, Middle, and Top Achievers. Considering the wide differences among these performance categories, there is the need for stakeholders in mathematics education to approach communication in the field conceptually or philosophically by discouraging students and other key players from singling out who is good at mathematics and who is not (Boaler, 2015). Students need to be given opportunities to struggle and fail and be made to believe that mistakes and struggle are good, particularly for mathematics education. Focusing on mathematics as a skill, just like any other skill learned in school, could help increase mathematical literacy and encourage more young people to enter the field (Dickerson, 2013). Convincing mathematics education students that they can make themselves smarter by hard work can lead them to work harder and get higher grades (Kimball \& Smith, 2013). Considering students like S31, S34 and S15 (Table 1) who are heavily language-dependent, sensitization by elegant stakeholders in mathematics education should expect that mathematical proficiency for them, will require careful cultivation and will develop slowly (Willingham, 2009).

The teacher's role in fostering productive mathematical discourse in the entire mathematics education programme is a central one. In addition to being responsible for creating the opportunities for students to engage in discussions, exploring, negotiating, and sharing knowledge, the teacher's own use of language while working with mathematics education students serves as an important example of communication (Boulet, 2007). Such exemplified use of language must cut across both the language-based and computationbased courses of the mathematics education programme. In this sense, lecturers in Nigerian higher education must continue to examine and adjust their own practice. 


\section{Conclusion}

The development of the concept of acquiring a foreign language using selected substantive subject matter is the result of social demand for fast and effective mastering of this language. The primary goal of this type of programmes is not to gain linguistic skills by learners, but in fact to master selected non-linguistic content thanks to its knowledge. Implementation of the concept of language and non-language content integration in all its manifestations faces many difficulties related to the need to create own didactic solutions, which places strain on teachers-practitioners. Teacher training programmes in Nigeria, to an extent, prepare teachers for this task. Within the Mathematics Education programme, for instance, there are course units like Mathematics Teaching Methodology, Teaching of Specific Topics in Mathematics, and other mathematical methods courses, all aimed at training mathematics teachers to be aware of the fact that they are at the same time teachers of the language used in mathematics. Building on this premise, this study has attempted to present the pattern of academic performance of mathematics education students across language-dependent courses and computation-dependent courses. Krashen's Monitor Model of second language acquisition and a few expositions from advances in neuroscience were presented as key theoretical foundations for the study. Selected empirical studies reviewed in this work affirms a significant positive relationship between language proficiency and academic achievement in mathematics, with a clarification on the difference in syntax of both areas.

The study adopts an ex-post facto research design using examination records of 48 mathematics education students to answer two research questions and test the two stated hypotheses. Analysis of the data obtained for this study revealed that 27 of the students are neither dependent on language nor on computation, while 20 are language-dependent and 1 computation-dependent. A paired-samples t-test indicates that there is a significant difference between the mean achievement scores of mathematics education students in language-dependent courses and computation-dependent courses. Further analysis of variance shows that the mean achievement gap is highest among Bottom Achievers but lowest among Top Achievers.

Evidence from this study has supported the assertion that hard working and determined students do considerably well in both computational areas and language areas. The pattern of performance across the two extremes may also be indicative of existing orientation of the students towards mathematics education. The outcome of this study showed only one student as computation-dependent, a sign that all may not be well about the students' mindsets towards computational mathematics. This issue raised here should quicken all stakeholders of mathematics education to contribute to the development of the right mathematical mentality among students.

Despite the robustness of this study, it appeared to be limited by the unavailability of empirical inputs from the subjects of the study. Future works in this area may consider designing a survey to corroborate the participants' perceived orientation to their eventual dependence extreme. An expansion of the sample size and area of coverage may also strengthen the generalizability of findings. 


\section{References}

Abah, J. (2017). Original higher education experience of graduating students of Mathematics education in Nigeria: An autoethnographic approach. Education Journal Education Journal, 6(6), 177-187. Retrieved from http://article.sciencepublishinggroup.com/pdf/10.11648.j.edu $.20170606 .13 . p d f$

Arsad, P., Bauniyamin, N., \& Manan, J. (2014). Students' English language proficiency and its impact on the overall students' academic performance: An analysis and prediction using neural network model. WSEAS Transactions on Advances in Engineering Education, 11, 44-53.

Boaler, J. (2013). Ability and Mathematics: The mindset revolution that is reshaping education. Forum, 55(1), 143-152.

Boaler, J. (2015). The myth of being 'bad' at Math. Retrieved from https : / /medium. com/ aspen-ideas/the-myth-of-being-bad-at-math-b8c823ac7f75

Boulet, G. (2007). How does language impact the learning of Mathematics? Let me count the ways. Journal of Teaching and Learning, 5(1), 1-12.

Butterworth, B. (2017). From fear of fractions to the joy of Maths. Retrieved from http: // www. mathematicalbrain.com/pdf /

Dickerson, K. (2013). 'I'm not a Math person' is no longer a valid excuse. Retrieved from http://www.businessinsider.com/being-good-at-math -is-not-about-natural-ability-2013-11? IR=T

Ebrahim, E. A., \& Dagnaw, M. A. (2015). Analysis of determinants influencing students' academic achievement in English and Mathematics subjects of ending classes of schools at Bahir dar and Debre Tabor Towns, Ethiopia. International Journal of Secondary Education, 3(6), 61-66.

Emaikwu, S. O. (2012). Fundamentals of research methods and statistics. Makurdi: Selfers Academic Press Limited.

Fite, G. (2002). Reading and Math: what is the connection? A short review of the literature. Kansas Science Teacher, 14, 7-11.

Hadhazy, A. (2011). Life's extremes: Math vs. language. Retrieved from http:// livescience.com/16897-math-language-dyslexia-dyscalculia .html

Henry, D. L., Nistor, N., \& Baltes, B. (2014). Examining the relationship between Math scores and English language proficiency. Journal of Educational Research and Practice, $4(1), 2$.

Hong, Y. (2008). On teaching strategies in second language acquisition. US-China Education Review, 5(1), 61-67.

Iji, C., Agbo-Egwu, A., \& Adikwu, O. (2014). Effect of metalinguistic learning approach on students' achievement in secondary schools statistics in Makurdi Metropolis, Benue State, Nigeria. Journal of Education and Practice, 5(9), 31-37.

Kimball, M., \& Smith, N. (2013). The myth of ' $i$ 'm bad at Math': Basic ability in the subject isn't the product of good genes, but hard work. Re- 
trieved from http://www.theatlantic.com/education/archive/2013/ $10 /$ the-myth-of-im-bad-at-math/280914/

Krashen, S. D. (1995). The natural approach: Language acquisition in the classroom. Hertfordshire: Prentice Hall Europe.

Krashen, S. D. (2002). Second language acquisition and second language learning. California: Pergamon Press Inc.

Martirosyan, N. M., Hwang, E., \& Wanjohi, R. (2015). Impact of English proficiency on academic performance of international students. Journal of International Students, 5(1), 60-71.

National Universities Commission-NUC. (2007). Benchmark minimum academic standards for undergraduate programmes: Education. Abuja: National Universities Commission.

Organization for Economic Co-operation and Development OECD. (2007). Understanding the brain: The birth of a learning Science. Paris: OECD.

Perez, T., \& Pugalee, D. K. (2009). The learning of Mathematics for limited English proficient learners: Preparation of doctoral level candidates. The Mathematics Education into the 21st Century Project, 481-485.

Prendergast, M., Faulkner, F., \& O' Hara, C. (2015). Language as a barrier to learning mathematics. International Conference on Barriers and Enablers to Learning Maths: Enhancing Learning and Teaching for all Learners, 1-15.

Prochazkova, L. T. (2013). Mathematics for language, language for Mathematics. European Journal of Science and Mathematics Education, 1(1), 23-28.

Pugalee, D. K. (2009). Language and Mathematics: A model for Mathematics in the 21st century. The Mathematics Education into the 21st Century Project, 1-4.

Roessingh, H., Kover, P., \& Watt, D. (2005). Developing cognitive academic language proficiency: The journey. TESL Canada Journal, 23(1), 1-27.

Sahragard, R., Baharloo, A., \& Soozandehfar, S. M. A. (2011). A closer look at the relationship between academic achievement and language proficiency among Iranian EFL students. Theory and Practice in Language Studies, 1(12), 1740-1748.

Tao, T. (2017). Does one have to be a genius to do Maths? WordPress, 12. Retrieved from https://terrytao.wordpress.com/career-advice/does -one-have-to-be-a-genius-to-do-maths/

Varughese, N. A. (2009). Language difficulties in Mathematics courses for students from non-English speaking backgrounds in the transition from secondary to tertiary education.

Virginia Department of Education. (2004). Mathematics: Strategies for teaching limited English proficient (LEP) students. Richmong, Virginia: Division of Instruction, 1-27.

Wall, S. (2016). State Math, English test scores are in: How did students do? Retrieved from http://www.pe.com/2016/08/24/state-math -english-scores-are-in-how-did-students-do

Willingham, D. T. (2009). Is it true that some people just can't do Math. American Educator, 33(4), 14-19. 